\title{
Ciencia y arte... A todas luces
}

\author{
José Ramón Hernández Balanzar
}

\section{Resumen}

En este artículo se describe A todas luces, diálogo de saberes entre ciencia y arte. Se trata de un proyecto que, fundamentado en el diálogo de expertos y estudiosos de la ciencia y el arte, busca promover entre los estudiantes de la escuelas de la RedPEA, la red de escuelas asociadas a la UNESCO, el trabajo artístico y científico en torno al tema de la luz desde ambas áreas del conocimiento. Aquí se aborda el origen del proyecto, los conceptos de donde parte, así como las instituciones involucradas y las actividades realizadas.

Palabras clave: A todas luces, luz, experimentación, ciencia, arte, estudiantes.

\section{LIGHTING DESIGN: DEVELOPMENT, PRACTICE AND EDUCATION}

\begin{abstract}
In this article we describe A todas luces, diálogo de saberes entre ciencia y arte. It is a project that, founded on a dialog of experts in science and art, seeks to promote among RedPEA students, the school network associated to UNESCO, the artistic and scientific work about light from both areas, science and art. Here we talk about the origin of this project, the concepts that it is based on, the institutions involved, and the activities it entails.
\end{abstract}

Key words: A todas luces, light, experimentation, science, art, students. 
"Ciencia y arte... A todas luces"

Es físico por la Facultad de Ciencias de la UNAM. Miembro del consejo editorial y coordinador general de los Encuentros Nacionales de Divulgación Científica de la Sociedad Mexicana de Física (SMF). Actualmente es parte del equipo del Museo de la Luz UNAM/DGDC.

\section{Introducción}

A todas luces, diálogo de saberes entre ciencia y arte es un proyecto que tuvo su origen en el año 2015 el marco de la reunión nacional de Coordinadores de la RedPEA, que es la red de escuelas asociadas a la unEsco y que en nuestro país están coordinadas por la Comisión Nacional de Cooperación con la unEsco bajo el auspicio de la Secretaría de Educación Pública (CONALMEX-SEP). La participación y coincidencia en la mencionada reunión de la doctora Ana María Cetto del Museo de la Luz (ML-UnAm) y de la maestra Graciela Ferreiro de la Asociación de Artistas Plásticos de México (ARTAC) provocó sinergia para que entre ambas instituciones representadas en sus personas, y a invitación de la conALMEx, se buscará la posibilidad de generar un foro de participación, discusión, diálogo e intercambio de ideas entre expertos, estudiosos y apasionados en ambos temas: ciencia y arte, con el fin de promover entre las niñas y niños estudiantes de la escuelas de la RedPEA el trabajo artístico y científico en torno al tema de la luz desde ambas áreas y esferas de conocimiento. Es por lo anterior, que en junio de 2016 a iniciativa e invitación del Museo de la Luz se llevó a cabo el Seminario "A todas luces, diálogo de saberes entre ciencia y arte" -foro en el que artistas, científicos y divulgadores expusimos puntos de vista, trabajos artísticos y colaborativos, e investigaciones en torno a la luz-.

\section{¿Por qué ciencia y arte? ${ }^{1}$}

Fascinación y seducción, atracción y rechazo... Para muchos, la ciencia no busca el orden y la igualdad entre las cosas, sino aspectos todavía más generales del mundo en su conjunto, tales como "la simetría", "la armonía", "la belleza", y "la elegancia"; aún a expensas, aparentemente, de su adecuación empírica, como 
por ejemplo la teoría general de la relatividad. Para los griegos la belleza tuvo siempre una significación enteramente objetiva. La belleza era verdad, constituía un carácter fundamental de la realidad. De ahí el famoso lema, tan significativo y usado a lo largo de la historia del pensamiento filosófico: "lo verdadero, lo bueno y lo bello convergen" (Pérez Tamayo, 2005).

En la misma ciencia más pura, la genialidad de los científicos ha sido ubicada, no en su inteligencia, considerada bastante normal, sino en una imaginación desbordada y muy fuera de lo común. De aquí que "la ciencia consiste en crear teorías", es decir, modelos imaginados, estructuras teóricas, analogías, alegorías, símiles y comparaciones para representar los significados posibles de las realidades que nos circundan. Todo esto liga la ciencia con el arte.

Albert Einstein se refería a la teoría cuántica diciendo que "tal teoría no le gusta", que "no le gustan sus elementos", que "no le gustan sus implicaciones", etcétera. Su asistente personal de investigación lo interpreta aclarando que "su enfoque [el de Einstein] tiene algo en común con el de un artista; que ese enfoque busca la simplicidad y la belleza" (Russell, 1975); que su método, aunque está basado en un profundo conocimiento de la física, es esencialmente estético e intuitivo; que, excepto por el hecho de ser el más grande los físicos desde Newton, uno podría casi decir que él no era tanto un científico cuanto un artista de la ciencia" (González Casanova, 2004).

El estudio de la relación ciencia y arte es, por sí mismo, bastante amplio, la fundamentación epistemológica de esa relación y su aplicación real o posible de ambos conceptos se asumen de manera particular en una de sus acepciones: la función cognitiva, es decir, como medio para la adquisición de conocimientos y de verdad.

El científico está convencido de que lo que demuestra científicamente constituye la verdad más firme y sólida. El filósofo piensa lo mismo cuando su razonamiento es lógico e inobjetable filosóficamente. Y el artista cree firmemente que con su obra de arte ha captado la esencia de la compleja realidad que vive. 
Bertrand Russell, considerado uno de los pensadores más lúcidos del siglo xx y, quizá, de toda la historia de la humanidad, dice que "la ciencia, como persecución de la verdad, será igual, pero no superior al arte" (Clark, 1972). Asimismo, Goethe señala que el arte es la manifestación de las leyes secretas de la naturaleza.

La pasión por la aventura hacia la ciencia y el arte nos permite tener una imagen distinta de quiénes somos, ir más allá de las imágenes clásicas y estereotipadas. Nos da, fundamentalmente, mayor amplitud, mayor versatilidad. Es decir, adquirimos una mayor capacidad de apreciar la enorme variedad de aspectos y propiedades físicas que tiene la naturaleza para su mayor entendimiento, en consecuencia. 


\section{A todas luces... conalmeX-ARTAC-Museo de la Luz unAm}

El desarrollo de las experiencias en las escuelas participantes de la RedPEA fue mediante actividades lúdicas, educativas y artísticas enfocadas a la educación para el desarrollo sostenible. El reto fue difundir este concepto a través de una aplicación/integración del fenómeno de la luz en procesos de creatividad científica y artística, dirigidos a estudiantes de primaria de las escuelas de la RedPEA en seis estados de la república mexicana. En los talleres impartidos por el Museo de la Luz, se vinculó la ciencia con el arte a través de diferentes fenómenos característicos de luminiscencias, fluorescencias, la suma y resta de los colores, la reflexión y refracción de la luz, ilusiones ópticas, y aspectos básicos y generales de luz y energía. 
La experiencia de vincular la ciencia sobre la luz con el aspecto lúdicocreativo en la construcción de objetos con un sentido estético-artístico produjo como producto en cada escuela un bello, útil y verdadero mural colectivo, que hoy forma parte del patrimonio artístico, científico y cultural de cada institución. El éxito de este proyecto permitirá que en 2019 siga formando parte de los Programas de Participación apoyados por la conalmex en la unesco. Así también, que sea un programa que se presente en más escuelas; y que se capaciten profesores normalistas, con el fin de replicar dicha actividad en años subsecuentes y se llegue a más estudiantes en diferentes estados del país.

\section{Referencias}

Clark, R. (1972). Einstein: the life and times. Nueva York, NY: Avon Books.

* González Casanova, P. (2004). Las Nuevas Ciencias y las Humanidades. Barcelona, Ed. Complutense, IIS-UNAM.

* Hernández Balanzar J. R. (mayo 2006). ¿Por qué ciencia y arte? Primer simposio de Ciencia y Arte en el Instituto de Ciencias Nucleares de la unam. México.

Russell, B. (1975). La perspectiva científica. Barcelona: Ariel.

* Pérez Tamayo, R. (2005). Arte y Ciencia [Entrevista de José Gordon]. Revista de la Universidad de México, 20, pp. 51-55.

\section{Cómo citar este artículo}

* Hernández Balanzar, José R. (2018). Ciencia y arte... A todas luces. Revista Digital Universitaria (RDU). Vol. 19, núm. 3 mayo-junio. DOI: http://doi.org/10.22201/ codeic.16076079e.2018.v19n3.a7. 